\title{
El diario de un escritor en Encuentro en Saint-Nazaire de Ricardo Piglia*
}

Fecha de recepción: 04 de septiembre de 2015

Fecha de aprobación: 25 de enero de 2016

\section{Resumen}

En este artículo estudiamos el género diario íntimo a través de la nouvelle Encuentro en Saint-Nazaire (1988) que contiene el "Diario de un loco" del escritor ficticio Stephen Stevensen. Este uso ficcional del diario, dentro del marco de la estructura de la obra literaria, adquiere un sentido diferente porque renuncia a la comunicación de algo íntimo y secreto, para convertirse en literatura, en "comunicación estética". Asimismo, pretendemos evidenciar la importancia y la magnitud del género diario en la unidad narrativa de un autor como Ricardo Piglia. Junto a esto, el ejemplo de Encuentro en Saint-Nazaire nos ayudará a mostrar las características de este tipo de prosa pigliana, que funciona como un laboratorio de la escritura.

Palabras clave: Diario íntimo-ficcional, escritor ficticio, Piglia.

Citar: Hernández Peñaloza, A.A. (enero-junio de 2016). El diario de un escritor en Encuentro en Saint-Nazaire de Ricardo Piglia. La Palabra, (28), 75-90. doi: http:// dx.doi.org/10.19053/01218530.4789

\begin{abstract}
Amor Arelis Hernández Peñaloza

CILHA-Universidad Nacional de Cuyo

Doctora en Letras Universidad Nacional de Cuyo, Argentina Profesora Universidad Nacional de Cuyo, Argentina amorcitohp@hotmail.com

* Artículo de reflexión producto de la investigación doctoral "Prácticas y poéticas de los géneros literarios en la obra de Ricardo Piglia", aprobada por el Doctorado en Letras, de la Universidad Nacional de Cuyo. Mendoza, Argentina (2013).
\end{abstract}




\section{la palabra}

\section{The Diary of a Writer in Encuentro en Saint-Nazaire [Meeting in Saint-Nazaire] by Ricardo Piglia}

\section{Abstract}

In this article we study the genre of the intimate diary through the nouvelle Meeting in SaintNazaire (1988), which contains the "Diary of a Madman" by the fictional writer Stephen Stevensen. Used within the structure of the literary work, this fictional diary takes on a different meaning, because it renounces the communication of something intimate and secret, and instead becomes literature, "aesthetic communication". This study also highlights the importance and magnitude of the journalistic genre in the narrative drive of an author like Ricardo Piglia. Additionally, this study of Encuentro en Saint-Nazaire [Meeting in Saint-Nazaire] will help show the characteristics of this type of pigliana prose, which functions as a laboratory of writing.

Keywords: Intimate-fictional diary; fictional writer; Piglia.

\section{Le journal d'un écrivain dans Une rencontre à Saint-Nazaire de Ricardo Piglia}

\section{Résumé}

Dans cet article nous étudierons le genre du journal intime à partir de la nouvelle Une rencontre à Saint-Nazaire (1988) qui contient le "Journal d'un fou " de l'écrivain fictif Stephen Stevensen. Cet usage fictionnel du journal, dans le cadre de l'écriture de l'œuvre littéraire, adopte un sens différent parce qu'il renonce à communiquer quelque chose d'intime et secret, pour se transformer en littérature, en " communication esthétique ". De la même manière, on met en évidence l'importance et la grandeur du genre du journal intime dans l'unité narrative de Piglia. L'exemple d'Une rencontre à Saint-Nazaire nous aidera à montrer les caractéristiques de ce type de prose, qui fonctionne comme un laboratoire de l'écriture.

Mots clés : Journal intime-fictionnel, ecrivain fictif, Piglia. 
Desde el punto de vista de la historia de las formas literarias, la manifestación del diario íntimo de un escritor como valor estético es atractivo porque cuestiona el concepto de privacidad, de sinceridad, de introspección, de documento, propia del diario en sus orígenes, y de su pertenencia a las formas denominadas "no ficcionales", en el mismo plano de las "escrituras del yo" comprometidas, según Lejeune, con la expresión de la verdad. A propósito de esta idea, Piglia (2000) comenta:

A mí me interesan mucho las vidas posibles, las construcciones imaginarias de la propia vida, y me parece que en un diario está todo eso. O sea: el sujeto dice la verdad, el sujeto es el sujeto de la verdad. Entonces, ahí hay un corte con la ficción, donde en realidad uno podría preguntarse qué es la ficción. (p. 41).

En este sentido, recordemos que con la publicación del diario de Amiel $^{1}$ se da el primer paso en la transformación de lo íntimo en público. Desde ese momento, se pone en entredicho la sinceridad y el grado de intimidad del diario. Una contradicción que confirmó Witold Gombrowicz (2005) en las primeras páginas de su Diario
(1953-1969), ocurre cuando apunta lo siguiente: "Escribo este diario con desgana. Su insincera sinceridad me fatiga. ¿Para quién escribo? Si es para mí mismo, ¿por qué lo mando a la imprenta? Y si es para el lector, ¿por qué hago como si hablara conmigo mismo?" (p. 61). Así pues, lo que acercaría al diario al dominio de la ficcionalidad es por un lado su publicación, porque se adueña de artificios comunicativos propios de los géneros ficcionales; por ello no es raro encontrar en él una trama narrativa pese a la fragmentación del discurso que nos produce el auténtico diario, da la impresión espontánea de la realidad y su fijación lingüística; y por otro lado, que la "intimidad, lo privado, lo sincero" es manipulada, transformada, arbitraria, rebuscada, recreada, imaginada, usada. Es decir, el diario pasa a ser:

[...] una técnica de la narración ficcional, una de las formas de la novela en primera persona junto con las memorias y la novela epistolar sus propiedades fragmentariedad, incoherencia, etc., adquieren un status semiótico distinto: se convierte en elementos y medio de expresión en el seno de la estructura de una obra. La escritura diarial, en la que no había comunicación al ser utilizada de un modo ficcional dentro del marco de la estructura de la obra literaria, pasa a ser, de un modo completamente nuevo, comunicación estética. Las formas del discurso propias del diario, que esencialmente estaban en contradicción con el concepto de totalidad propia de la obra, en cuanto formas artísticas, colaboran ahora a la constitución de una totalidad. (Picard, 1981, p. 119).

De esta manera, se hace posible la utilización del diario como "artificio literario" y su correspondencia con la vida del autor carecería de importancia. Además, teniendo en cuenta que en las escrituras del yo: "La ficción y la verdad están juntas y separadas al mismo tiempo y el borde inextenso; ese gozne invisible que las anuda y desanuda sin cesar no es otro que el autor, el nombre propio del autor y el concepto mismo de autor." (Campillo, 1992, p. 26). Percibimos entonces que en el caso del diario, se confirma la identidad entre quien firma la obra, el narrador y el autor. Sin embargo, cuando se usa el diario en la ficción, se observa,

\footnotetext{
Henri-Frédéric Amiel fue un filósofo y escritor suizo (1821-1881) quien publicó en vida algunos fragmentos de su "diario íntimo" cuando era todavía un género esencialmente privado. Sería justamente, como señala Girard, la publicación póstuma del diario de Amiel lo que contribuiría decisivamente "a operar la conversión de esa escritura 'para uno mismo' en una escritura para el público, y la transformación del diario en verdadero género literario". (Tomado de la presentación del libro En torno al diario íntimo de Amiel. Traducción de Laura Freixas. Editorial Pre-Textos, 1996).
} 
se refleja y se recrea la realidad por medio de un autor que se oculta, que se disfraza, que desaparece tras el narrador, tras los personajes, tras los nombres propios ficticios, tras las máscaras y tras la pluralidad de sus voces. Hasta tal punto que las manifestaciones del "Yo narrador" en el diario son confusas e indefinidas, "el diarista es una persona ficticia", inmerso en un mundo estético, literario, ajeno, impropio en donde todo cabe y se borran los límites entre lo público y lo privado, entre lo verdadero y lo falso.

Ahora bien, Encuentro en SaintNazaire $^{2}$ (1988) es una nouvelle que relata el encuentro de dos escritores en la ciudad costera de Saint-Nazaire, al norte de Francia. Estos dos personajes están allí gracias a la invitación de la Maison des Écrivains et Traducteurs Étrangers (MEET. France), asociación que invita a residir en el lugar a un escritor o a un traductor, y se les propone un pacto: producir o traducir un texto que tenga que ver con sus días en la institución. La historia comienza con la llegada de un narrador escritor argentino, el miércoles 4 de mayo de 1988 y el encuentro con Stephen Stevensen, escritor irlandés, un día antes de la partida de éste en un restaurante cerca del puerto. Dice el narrador:

Llegué por primera vez a Saint-Nazaire un miércoles, el jueves Stevensen me llamó por teléfono y me invito a almorzar (fue el jueves 5 de mayo). Parecía inquieto, parecía como si conocerme fuera una exigencia ineludible, una de esas obligaciones sociales que no se pueden evitar. [...] Desde hace años escribía un Diario. (p. 91).

A partir de la aparición de Stephen Stevensen, la vida del narrador-escritor se ve transformada debido a que lo hace partícipe de un descubrimiento: "el diario que tiene funciona como un oráculo, porque predice el futuro, todo lo que Stephen escribe se realiza." (Estrade, 2007a). El narrador, incrédulo frente a esta revelación, halla un sobre con su nombre que contiene varias páginas del diario "escritas la semana anterior de mi llegada a Saint-Nazaire" (p. 106). El diario describe, además de otros sucesos, el encuentro que acaba de darse entre los dos escritores, y lo que se alcanza a leer en el diario son los hechos que adivina el visionario Stephen Stevensen, acerca de lo que hace o va hacer el narrador; "y capaz de prever el futuro, escribe lo que sucederá mañana: se trata del poder de la ilusión." (Pereira, 2001, p. 36).

Lo curioso es que, en 1988 Ricardo Piglia es efectivamente invitado a pasar un par de meses (entre enero y marzo) en la Maison des Écrivains Étrangers et des Traducteurs y, el resultado de su temporada allí es Encuentro en Saint-Nazaire. En esta obra, el autor apela a la ficción para referir su estadía, pero también hace una inscripción de su empresa autobiográfica.

A pesar de la falta de compromiso o de pacto autobiográfico ${ }^{3}$, es decir, la ausencia de una intención de comunicación, inmediata o diferida en la cual el "autobiógrafo pide al lector que confíe en él, que le crea, porque se compromete a contarle la verdad" (2004, p. 649), consideramos los índices de la ficción como síntomas de intención autobiográfica en Encuentro en Saint-Nazaire. Por esta razón, vinculamos al personaje y el narrador con el autor y su mundo efectivo; sondeamos y detectamos cuánto del autor hay en el narrador y

2 Todas las citas pertenecen a la edición: Piglia, R. (2007). Encuentro en Saint-Nazaire. [1988]. En Prisión perpetua. (pp. 79150). Barcelona: Anagrama.

3 Recordemos que Lejeune (1991) llama "pacto autobiográfico" al contrato que constituye a un texto como autobiografía, en donde la identidad es sellada "por el nombre propio. Y eso es verdad también para quien escribe el texto. Si yo escribo la historia de mi vida sin decir mi nombre, ¿cómo sabría el lector que se trata de mí? Resulta imposible que la vocación autobiográfica y la pasión de anonimato coexistan en el mismo ser." (p. 55). 
en el personaje hasta descubrir que la historia ficticia tiene un evidente compromiso con la vida de Piglia. Esto lo advertimos parcialmente, pues nunca tendremos completa seguridad de la correspondencia entre la vida del autor y lo que la nouvelle relata. Al respecto, Piglia (2008) comenta:

[...] la novela corta Encuentro en Saint-Nazaire, el juego de lo autobiográfico está presente como elemento de construcción. Parto de la autobiografía, de los rastros de la experiencia, digamos, y de la verdad de lo que he vivido confrontando las distintas versiones que tengo de mi propia experiencia. Hay cosas que uno recuerda con mucha nitidez, momentos vividos que no necesariamente son tal cual como uno los recuerda. En el caso de mis textos, la autobiografía ha sido un punto de partida a partir del cual he tratado de construir alternativas, otras vidas posibles.

Aunque Piglia no especifica su nombre en Encuentro en SaintNazaire, usa la primera persona $\mathrm{y}$ el narrador es un escritor argentino. De la misma manera, el diario como modelo narrativo en Stephen Stevensen "nos sitúa sobre la pista del doble literario, que el narrador confirma al atribuir a Stevensen algunos rasgos reconocibles que el propio
Piglia desea para sí." (González, 2009, p. 131). Esta reelaboración de la experiencia por parte del autor en la Maison des Écrivains, viene a ser una puesta en abismo de la naturalización de la ficcionalización, esto es, rompe su distinción con la realidad. Esta naturalización se produce cuando los sucesos reales (los personajes, las citas, los lugares, las fechas indistintamente) que habitan la nouvelle se nivelan narrativamente con los imaginarios al mejor estilo pigliano. Así, por ejemplo, el narrador utiliza una "Posdata", como presentación del "Diario de un loco", título de la segunda parte de Encuentro en Saint-Nazaire, para contarnos lo que se indica a continuación:

Al día siguiente viajé a Londres y me perdí en ese laberinto rojo y no encontré rastros de Stephen. Tiempo después conocí los escritos que ahora incluyo y que fueron publicados por la revista Granta en el número de homenaje a Stevensen, en diciembre de 1988, con el título de A Personal Dictionary. Son restos de sus Diarios ordenados alfabéticamente y muchos de los materiales que he citado no están en esta versión. Parecen ser lo único que ha sobrevivido de sus experimentos personales, ¿qué ha pasado con el resto? Tal vez las páginas que siguen son la respuesta; están ligadas a la memoria de los hechos que he escrito y la traducción del inglés me pertenece (así como el título, que expresa mi opinión sobre el autor). (p. 110).

De igual forma, vemos una "Nota" al final del libro Prisión perpetua, donde fue publicada la nouvelle, firmada por R.P. Apreciamos no sólo las iniciales de Ricardo Piglia, sino que además leemos una especie de confesión del autor que dice: "he contado fragmentos de mi vida" y aclara al final de la misma que:

Encuentro en Saint-Nazaire fue escrito durante una estadía de tres meses en la Maison des Écrivains Étrangers et des Traducteurs de Saint-Nazaire. Los extraños sucesos que ocurrieron en ese lugar no empañan el recuerdo de los bellos y brumosos días que viví en el Building y tampoco el agradecimiento a mis amigos de la Maison y en especial a su director, Christian Puskas [...]. Puskas trató de prevenirme sobre lo que me esperaba pero previsiblemente no lo comprendí. La noche en que llegué me recibió en la estación de trenes y en un idiolecto, que me sonó al principio como una declinación bretona del húngaro, me dijo (ahora lo sé) que no le diera mi 
confianza al huésped que había abandonado la casa la noche misma de mi llegada. [...]. Apenas podemos comprender lo que dicen los amigos, ¿cómo podía yo adivinar lo que ese hombre, a quien veía por primera vez, trataba de decirme? El relato que he escrito es un efecto de esa incomprensión y también un efecto de la telaraña verbal que Stevensen tejió a mi alrededor. (p. 150).

Por lo anterior, podemos deducir que en la nouvelle los diferentes niveles narrativos se fundan poco a poco en uno solo, generando la autoficción ${ }^{4}$, en donde el narrador lee y publica el Diario de Stephen Stevensen y se desarrollan la ideas piglianas de que "la verdad está en la lectura de la ficción" y que desde la lectura "No se va de la ficción a la vida, sino de la vida a la ficción. Lectura y vida se cruzan, se mezclan." (2005, p. 179). De este modo, Encuentro en Saint-Nazaire va y viene entre el registro ficcional y autobiográfico, que siendo incompatibles por principio, quedan fundidos y homogenizados para hacerse uno por medio de una estrategia desconcertante y transgresora que encontramos del autor para autoficcionalizarse de manera ambigua, con disimulo y ocultamiento entre juegos especulares, imposturas literarias, autores inexistentes y obras apócrifas como "Diario de un loco", modelo de diario en el que la relación con lo real y lo ficcional juega a la desaparición de los límites.

Pareciera que para Piglia el diario permite las experiencias de roles al asumir las distintitas identidades y lugares de la enunciación, como si los efectos se resolviesen desde otro lugar, donde la espontaneidad de un escrito abre un abanico de posibilidades, de lecturas, con solo intercambiar roles. (González, 2008, p. 167).

Sabemos que Ricardo Piglia escribe un diario desde los 14 años motivado por una situación de crisis que recuerda de la siguiente manera: "Empiezo a escribir el diario cuando mi familia decide que nos tenemos que mudar a Mar del Plata y siento que mi casa y mi vida están desmanteladas. Hay un sentimiento y la escritura reacciona." (2012). Con el exilio, comienza la escritura del diario y el descubrimiento de la propia realidad de escritor. Según Berg
(2000), para Piglia el diario sería "ese mito de origen":

Un relato iniciativo, de pasaje y corte, que circula en algunos relatos y entrevistas: una escena arcaica lanzada hacia el futuro en forma de Diario. Diario privado que configura una mitología autoral el sujeto de la escritura que Piglia inventa- así como una autobiografía por venir. Sus textos son fragmentos de ese libro futuro mitológicamente tangible, umbral último de su poética. [...] es un relato interminable y secreto; un work in progress constituido en el constante aplazamiento y dura lo que dure la experiencia de la escritura. (p. 67).

Por eso, Piglia concede a su diario personal un lugar significativo a tal punto que parece la columna vertebral de toda su obra porque es el motor y el origen de sus ficciones, debido a que en él "entra todo". Dice el autor:

Muchas veces un diario acompaña la escritura de un libro; entonces, tomo notas de un relato que estoy escribiendo, fragmentos de cuentos, diálogos o situa-

\footnotetext{
$4 \quad$ La autoficción, palabra inventada por el escritor Serge Doubrovsky en 1977, significa "ficción de sucesos y de hechos estrictamente reales". Por otro lado, según Manuel Alberca, el rasgo característico de la autoficción se fundamenta en confundir persona y personaje o en hacer de la propia persona un personaje, insinuando, de manera confusa y contradictoria, que ese personaje es y no es el autor. Al respecto escribe: "En la autoficción los elementos biográficos del autor, conocidos y desconocidos, irrumpen en la historia como material narrativo en bruto, coexistiendo abierta o sutilmente junto a otros que son o parecen ficticios." (2007, p.131).
} 
ciones ligadas: podríamos llamarlas 'notas de trabajo'. Pero hay otros apuntes que no son de lectura sino intentos de sintetizar algo. Habitualmente, la escritura de un libro me produce cosas que pertenecen al ámbito del diario y no a un plano distinto de reflexión. También me pasa que cuando termino los cuadernos encuentro cartas, cuentas o números de teléfono que fui guardando. El diario es una especie de archivo raro, como un corte geológico de lo que estaba sucediendo en ese momento. Un cajón, un lugar donde se guardan muchas cosas. (2012).

De ahí la importancia esencial del género diario en la obra pigliana, ya que podemos suponer que si alguna vez accedemos a la lectura del diario o de "los cuadernos azules" de Ricardo Piglia, encontraríamos plasmados no sólo pensamientos y sentimientos íntimos del autor, sino muchos de los relatos y de las ideas realizadas y enunciadas en sus obras, pero aquí aparecerían quizá sin corrección, sin estar revestidos de personajes como: Emilio Renzi (alter ego emblemático del autor) y Stephen Stevensen. En este sentido, González Álvarez (2009) afirma que:

La imbricación del diario en la textualidad de Piglia pone en circulación dos nociones fundamentales: de un lado la nominada expresión de la alteridad, en tanto que los heterónimos de Stephen Stevensen y Emilio Renzi quedan desconcertados en el escrutinio de sus respectivos diarios y ven difuminada su identidad en favor de la noción del doble; de otro la ficcionalización de tales diarios depara un efecto de especularidad toda vez que estos no constituyen sino una prolongación de los cuadernos íntimos e inéditos que dice acumular el autor. (p. 151).

En Encuentro en Saint-Nazaire, el compromiso diarístico de Ricardo Piglia, puede ser rastreado a través de señales como:

- La práctica común entre Ricardo Piglia y Stephen Stevensen de llevar un diario, cuestión sobre la que el autor argentino declaró: "el diario es lugar de depósito imaginario, de usina o de horno en el que se cuecen los proyectos y las alternativas." (Bratosevich, 1997, p. 294). Por su parte, Stevensen "Desde hacía años escribía un Diario y pensaba usar esas miles de páginas escritas a lo largo de su vida como material para un experimento filosófico." (p. 92).

- Opiniones personales sobre la escritura de la nouvelle y fórmulas de autojustificación, por medio de las informaciones paratexuales (entrevistas, declaraciones públicas, notas, comentarios), donde Piglia señala el carácter autobiográfico de su texto ficcional.

- El uso del yo narrativo propio del género donde se funden, en el proceso de enunciación, la vida del autor con la voz del narrador y la de Stephen Stevensen. Estas toman posesión del mundo y de la experiencia de Piglia.

- La autoficción, incluso al ser anónimo el nombre del narrador, deja ver a un Piglia que se reinventa y erige como

\footnotetext{
$5 \quad$ A fines del año 2015, Ricardo Piglia publica Los diarios de Emilio Renzi. Años de formación, primer libro de una trilogía (Los años felices y Un día en la vida) que reúne los diarios escritos por el autor entre 1957 y 2015 . Por otra parte, el director de cine argentino Andrés Di Tella estrenó en septiembre de 2015 la película que lleva por título "327 cuadernos", donde los diarios de Piglia son los protagonistas. Al respecto, Di Tella (2015) indica: "Es un cuento que estoy contando, una especie de leyenda de un hombre que tiene todos esos cuadernos y trata de contar su vida. $Y$ todo lo que tiene que hacer para contarla, los experimentos, escribir en tercera persona, entregarle su vida a Renzi. Yo me doy cuenta de que casi todo lo que cuenta en sus novelas tiene base en la realidad y se vuelve es ficción. Como la operación que hace ahora, lo del diario de Emilio Renzi, que convierte sus diarios en ficción. Entonces leés más la fábula y menos el detalle oculto. De todos modos, creo que todo es muy real”.
} 
personaje de su ficción por medio del narrador-escritor argentino y de Stephen Stevensen.

- La metaficción, puesto que incorpora reflexiones sobre el género como:

- Por medio de la lectura del diario se revisa toda la vida, se relee el pasado personal y puede dar pistas para orientarse en la "selva oscura de la vida." (p. 96).

- En esos diarios "había algo escrito que él nunca había leído, un enigma que tenía que descifrar y que le permitiría entenderlo todo." (p. 96).

- El diario elaborado como "series de acontecimientos, con el concepto de serie, con el concepto de serialización. Me interesaban sobre todo las descripciones laterales, los detalles sin importancia que había anotado al narrar cualquier situación.” (p. 98). - El diario es como "una máquina biográfica. Trabajaba con segmentos combinados y divisiones cada vez más pequeñas de mi vida." (p. 98). - En el diario los hechos se repiten: "Los mismos acontecimientos parecían una y otra vez." "El diario se convierte en un jeroglífico: Había un lenguaje secreto escondido entre las palabras." (p. 99).

- El diario debe ser leído como un oráculo. (p. 101).

- En "Diario de un loco" encontramos la elaboración de relatos en clave para mostrar aquellos ambientes y personajes que le interesan al autor, además de narrar sobre lo que conoce y frecuenta: literatura, política, libros y lenguaje.

Así pues, se genera en la nouvelle un espacio ambiguo entre realidad y ficción que deviene en un auténtico juego entre la vida privada personal y el público literario. Encuentro en Saint-Nazaire es en efecto un relato dentro del cual encontramos trazos o marcas autobiográficas de Piglia, explícitamente su estadía en la Maison des Écrivains Etrangers et des Traducteurs à Saint-Nazaire, además contiene un diario que recuenta fragmentos de la vida de Stephen Stevensen, quien es el autor de "Diario de un loco". El narrador, como lo habíamos mencionado arriba, llega a Saint-Nazaire "para encontrar a Stephen Stevensen. Pero quizás no debo escribir 'He vuelto' o 'He decidido volver.' Quizás debo escribir que él ha decidido que yo vuelva a Saint-Nazaire para encontrarlo. ¿O para no encontrarlo? (Él es Stephen Stevensen)."(p. 81).

Sumado a lo anterior, en la nouvelle el narrador expone su experiencia en la Maison des Écrivains Étrangers et des Traducteurs. Entonces se ve obligado a hablar de los recuerdos que tiene del encuentro con Stephen Stevensen y sobre todo, del diario que escribe, porque ahí: "los esbozos ficcionales que Stephen Stevensen ensaya en su diario no hacen sino anticipar la conducta del narrador, que se convierte en objeto de tales experimentos literarios." (González, 2009, p. 131).

En Encuentro en Saint-Nazaire, el diario es recompuesto y reescrito por el narrador como "Diario de un loco", a saber: estamos en frente de un diario ficcional, una analogía de la escritura pigliana, en cuyo estilo la literariedad ocupa el lugar primordial al dar una forma estética plausible al relato. Esta narración, plena de literatura, está condicionada por el conjunto textual en la que está inserta, donde los límites se vuelven difíciles de establecer entre un "verídico" diario (el de Piglia) bajo el nombre de otro autor (Stephen Stevensen) y el texto adaptado por el narrador. Es decir, se crea un juego de cajas chinas cuando Stevensen es citado por Piglia

[...] que a su vez acabaremos entendiendo como un narrador-autor citado en la totalidad del texto por el propio Stevensen, cuyo poder matemático de anticipación documentado todo a lo largo en sus confidencias a Piglia y otras prácticas sorprendentes y abrumadoras corroboraría la sospecha de que Un encuentro en SaintNazaire ha sido (pre) escrito 
por Stephen antes de que sucediera el encuentro -las fechas cantan. Y de que Piglia-autor es un autor-escriba, o mejor viceversa ya que la escritura anticipada puede suponerse ignorada por el propio Piglia escritor, copiador-copiado o Pierre Menard de doble dirección, leído por quien lo pre(e) escribe y personaje de un autor (Stephen) que a su vez es se pretende que sea personaje de Piglia. (Bratosevich, 1997, p. 19).

Por lo referido anteriormente, corroboramos que Encuentro en Saint-Nazaire trata de escritores y sobre lo que les pasa en el proceso de la escritura y de la lectura, "Piglia-Stevensen escriben-leen, la tarea nunca extinguida de leerescribir, con guiños a un lector cómplice a quien estimulan para entrecruzar su trama en lo tupido del tapiz." (Bratosevich, 1997, p. 29). De esta forma, en la nouvelle se establece un paralelo entre leer y escribir, donde ambas acciones son vividas simultáneamente. El escritor se construye al mismo tiempo que reconstruye a través de su experiencia otro escritor, otro lector. Acerca de este asunto, Piglia (2000) dice: "Los escritores construimos tramas imaginarias, lazos, con otros escritores, y ése es un gran espacio de luchas de poéticas de cada uno. E1 modo como uno constituye una tradición tiene que ver con el modo en que uno espera ser leído.” (p. 26).
El narrador de Encuentro en Saint-Nazaire es un escritor que lee el diario de Stephen Stevensen en el cual descubre que este autor lleva un registro de sus movimientos, de sus experiencias. Veamos:

En las primeras anotaciones Stevensen se movía a ciegas. No conocía mi nombre. Me llamaba el 'argentino'. O simplemente me llamaba 'Él'. De a poco los borradores se iban haciendo más precisos. Stevensen escribió con increíble seguridad. Era una ventaja haber vivido en la misma casa donde yo estaba viviendo. Podía imaginar mis desplazamientos, mis hábitos. Lentamente empezó a anticipar mis movimientos. El Diario podía haber sido escrito por mí. (pp. 106-107).

Los hechos que lee el narrador alcanzan un carácter específico, ya no es únicamente un escenario sobre el cual se representa como personaje, sino que sus contactos y sus relaciones entran por vías significativas en la escritura de Stevensen y se adquiere una dependencia importante entre los dos escritores. En relación con esto, el narrador se refiere a Stephen Stevensen del siguiente modo: "En realidad había decidido que yo formaba parte de sus experimentos y quería estudiar mis reacciones. Ahora comprendo que me vigilaba, o que estuve bajo su observación desde que llegué." (p. 83). Así, el narrador advierte cómo su vida ha sido prevista minuciosamente desde su arribo en Saint-Nazaire. "Es por ello que al llegar al estudio de Stephen y encontrar un mensaje en la computadora en el que le dice conocer su destino final decide desenchufar la máquina." (Quintana, 2001, p. 98). O sea, las experiencias del narrador son integradas a la escritura de Stephen Stevensen y se convierten en una memoria privada que, sin embargo, habla de otro.

El narrador es un personaje fabricado por Stephen Stevensen como un hombre de letras, lector y escritor que tiene las mismas características del diarista, articulando "El relato doble o el relato espejo (donde queda comprometida la relación entre autor-autor, autor-lector y perseguidor-perseguido)." (Bratosevich, 1997, p. 20). El narrador es el lector del diario de Stephen Stevensen, quien publica y reescribe como "Diario de un loco", no obstante él es atrapado en la tela ficcional del diario de Stevensen. Por consiguiente, lo vemos inmerso en "Diario de un loco" bajo el sobrenombre "Argentino":

AVENTURA: El argentino ha entrado subrepticiamente en la Maison des Ecrivains Etrangers et des Traducteurs y al cerrar la puerta y enfrentar el amplio 
ventanal que da a los muelles oye sonar el teléfono, en el rincón más remoto del cuarto. [...] El argentino (su irrupción) no ha hecho más que interrumpir una serie secreta. Ahora quiere actuar, es decir, quiere ampliar el campo donde va a ser observado. (p. 112).

CELOS: El argentino baja del tren de la Gare de Lyon y va hacia Erika (tiene una cita). Encuentra a una conocida por azar en el subte, tiene una conversación amable y nerviosa. Está, le dice, de paso hacia Florencia. La mujer quiere cenar con él esa noche, el argentino baja precipitado en Pigalle y se pierde en los corredores blancos. (pp. 114-115).

En el caso de Stephen Stevensen, se trata de un escritor que inmerso entre la realidad y la ficción, está condenado metafóricamente a escribir un diario, proyecto que "consiste en lograr un sistema de cálculos que puede anticipar el porvenir. Dicha cuestión lo conduce a leer su diario como si fuera un oráculo." (Quintana, 2001, p. 97). De manera que Stephen Stevensen también es "un adivino. Es esa práctica justamente lo que lo lleva a predecir el futuro de su amigo." (Quintana, 2001, p. 98). Por ende, Encuentro en Saint-Nazaire, es ante todo una nouvelle sobre la experiencia de la escritura, cuyo sujeto principal es el del trabajo literario de los escritores, donde el diario es herramienta indispensable debido a que es el banco de prueba, es el depósito, es el juez, es la cabida de todo, etc. El diario ya no es más la confidencia de un hombre, sino "el laboratorio de la escritura que concede beneficios por su funcionamiento, porque no es resolutivo, no es acabado, sino evolutivo y constantemente en proceso." (Didier, 1976).

Por lo anterior, también entendemos por qué la nouvelle está enmarcada en el contexto de la Maison des Ecrivains Etrangers et des Traducteurs à Saint-Nazaire, lugar dedicado a la escritura "perfecto para trabajar" (p. 96), dice Stevensen, en donde el autor imagina a un escritor, a "un hombre relato que despliega su baraja de historias sin fin" (Bratosevich, 1997) que se reproducen en "Diario de un loco". Relato que hemos concebido como un "verdadero" diario, no solo porque su título lo indica sino porque constituye una historia de vida, la memoria de un itinerario existencial que presenta las transformaciones de una trayectoria personal, tanto de Stephen Stevensen como del narrador-escritor y del autor Piglia. Asimismo, "es un ejemplo de la relación que se articula en torno a la idea según la cual la escritura de la obra debe acompañar la vida entera de un artista y confundirse en ella." (Orecchia, 2006, p. 254).
"Diario de un loco", en vez de estar compuesto por una serie de entradas fechadas, está escrito bajo la forma de un diccionario, instancia genérica que permite a la sucesividad narrativa subordinarse a las letras del alfabeto; compuesto por una treintena de palabras que cobijan asociaciones e ideas sobre el oficio del escritor, así como escenas independientes y relatos que llaman otros relatos, conceptos acerca de la lectura, de la historia, de la literatura, indicios de narraciones, produciendo transformaciones textuales que son el corazón de la dinámica de la escritura de Piglia y fundan su poética. Es decir:

Bajo la rúbrica del irlandés vuelve a facilitarnos las claves de su poética por una vía fragmentada y oblicua, la de un peculiar diariodiccionario sobre el cual el escritor ficticio articula una serie de anotaciones ordenadas alfabéticamente y segmentadas a su vez en varias acepciones que contiene por igual reflexiones metaliterarias, datos científicos y esbozos de relatos. (González, 2009, p. 137).

Incluso, cada anotación podría considerarse como algo separado del texto global y con autonomía propia. Empero, dentro del conjunto de "Diario de un loco", cada una de éstas se considera como algo inacabado, incompleto debido a su organización 
que no aparece esquematizada a la manera tradicional del género, transgrediendo así "el caos fragmentario" del diario, utilizando la disposición alfabética del diccionario para elaborar pedazos de historias que son introducidas por las siguientes palabras: Autor; Aventura; Ben Juslin; Caso; Celos; Deducción; Destino; Diario; Diccionario; Dicho; Difracción; Experiencia; Fábula; Fermat; Pierre; Final; Hermana; Inmóvil; Intriga; Irlanda; Kamikaze; Matemático; Muerte; Negación; Porlock; Quiasmo; Repetición; Reyes; Sitiada; Teje; Traducción; Visión.

"Diario de un loco", bajo la forma de un diario-diccionario, dibuja un espacio experimental "a medio camino entre el registro íntimo, el apunte narrativo y el ensayo especulativo." (Berg, 2006, p. 48). Stephen Stevensen, el diarista, se mueve en él sin totalizar ninguna historia, produciendo en cambio fragmentos inconexos de la misma o diferentes historias entramadas caóticamente y desordenadas, pero impactantes y paradójicamente sólidas. De esta manera, pone de manifiesto:

[...] un fervor por el relato que Ricardo Piglia exhibe con formulaciones, marcos y extensiones variables: ficciones apenas insinuadas conviven con textos más amplios y una galería de familiares que se incorporan en el acto coral de la narración, enmarcado en un espacio insólito y restringido: el de un diccionario con entradas léxicas, algunas de ellas basadas en cuestiones científicas [...] Apuntes metanarrativos sobre los que Piglia erige una autoficción, fragmentando las vivencias. (González, 2009, p. 144).

Cada palabra del diariodiccionario, es un fragmento de un discurso sin concluir que remite a una escritura, a una historia posible, a una idea. Se pasa de un orden de enunciación a otro, produciendo intersticios, resquicios, grietas, un conjunto de segmentos de la experiencia de un escritor presente de manera variada y abstracta a través de personajes e interlocutores que en el fondo se encuentran parecidos y con similitudes; protagonistas de una búsqueda literaria que nos muestran una intimidad intelectual permanente por medio de situaciones y cuestiones diferentes, pero en las cuales se percibe siempre la voz directa de Stephen Stevensen y la voz oblicua de Piglia. Además, observamos que la autoreferencialidad por parte del escritor Stephen Stevensen se impone como vertebración discursiva, superpuesta a la temática de hacer un diario sobre un relato ficcional contado por un escritor también ficcional que autoficcionaliza a Piglia y que manifiesta la intención auto- biográfica del autor. Al respecto, dice González (2009):

El diario comparece ante nosotros como apropiación y construcción de la alteridad, en una doble dinámica de direcciones opuestas; apropiación en cuanto Piglia espiga, reescribe y se atribuye vivencias ajenas; y construcción en la medida en que enhebra su historia "como si fuera la de otro", práctica ésta que encausaría al autor bajo los onerosos "cargos" de falsificación, robo, atribución apócrifa y tráfico de citas falsas. (p. 147).

Piglia-autor revela en la escritura diarística de Stephen Stevensen su espacio autobiográfico. Aunque su imagen en el relato carece de una formación, de un desarrollo verdadero, reconstruye, eso sí, algo de su personalidad, de su experiencia. De esta forma provoca un desdoblamiento autobiográfico, fenómeno frecuente constatado por los autores de un diario. Al mismo tiempo, "Diario de un loco" nos muestra al escritor en tanto que objeto y sujeto de su discurso. Vemos su imagen secreta, la que se revela en el diario, lugar de un extraño "teatro de máscaras" donde el escritor está tentado a desenmascararse (Didier, 1976). Esto es, el diario ficcional de Stephen Stevensen, funcionan como mecanismo "de retornos, de espejamientos, de inserciones 
y reciclajes (la aventura doble del perseguidor-perseguido y su contra cara, en cada uno de ambos protagonistas, pasaría a leerse como una alegoría más de la multiplicación de los reflejos discursivos.)" (Bratosevich, 1997, pp. 21-22).

Piglia, por medio de Stephen Stevensen, reescribe su diario y sus lecturas para poner en funcionamiento su crítica y su teoría sobre la literatura: vamos de un escritor en acción al lector-escritor que se burla y se autocrítica a sí mismo en los textos que lee. En otras palabras, Piglia se ve a través de los otros como puede y quiere. Como escribe Stephen Stevensen en el parágrafo sobre el AUTOR: "Nadie puede decir nada sobre sí mismo, pero sobre otro es posible, quizá en ciertas condiciones 'particulares' prever (y adivinar), como quien descifra su propio destino, el nudo que ata el sentido.” (p. 111).

Por lo antes expuesto, la intención de autoficcionalización en "Diario de un loco", se hace evidente y es, como explica Orecchia (2006): "un auténtico ejercicio de invención que consiste en insertar datos verosímiles o susceptibles de haber pertenecido a su experiencia [...] dentro de un relato perfectamente ficticio." (p. 254). Entonces, la dualidad ficción-realidad recorre todo el universo literario de "Diario de un loco": Primero, porque Piglia intenta transmutarse en la ficción creando un universo imaginario habitado por personajes, en los cuales los pensamientos y las actitudes no son muy diferentes a los suyos. Parece, como dice Bratosevich (1997), que para el autor entre vivir y contar no parece delinearse un deslinde tajante:

[...] puesto que nuestras historias contadas son las que nos construyen, como individuo y como grupo, así como constituyen el mundo, su sentido, la apreciación o depreciación que nos merece unas u otras zonas del mundo. El discurso, y en él la infaltable multiplicación de relatos con que nos definimos y juzgamos, refutándonos o corroborándonos, es pues la 'prisión' donde transcurrimos sin tregua. (p. 322).

Dicho de otra manera, por medio de la configuración de la experiencia, Piglia encuentra la forma más conveniente para hablar de sí mismo, de sus lecturas y de su escritura "un modo de que sospechemos que Piglia acaso transcribe, so capa de cita ajena, tramos de sus reflexiones personales anotadas en el Diario que continúa escribiendo." (Bratosevich, 1997, p. 317) Es más, Piglia escribe desde la escritura y las lecturas que lo inspiran, interesándose sobre todo por los procedimientos de los otros escritores, los cuales le suscitan comentarios sobre problemas propios de los estudios literarios, que se ven reflejados tanto en sus libros de crítica como en sus ficciones. Por ejemplo, en "Diario de un loco" encontramos reflexiones sobre:

- La no pertinencia del concepto de verdad en la literatura.

- El valor genético de la repetición y la variación.

- La desaparición de la idea de original.

- La relación entre experiencia y escritura. (Orecchia, 2006, p. 252).

Segundo, porque la mezcla de datos personales verdaderos y falsos genera "una transparencia engañosa" y une dos propiedades que se excluyen mutuamente y lo hace quitándole a la intimidad, a lo privado, el carácter subjetivo. Las condiciones de la escritura subjetiva que Piglia emplea se basan en la ficcionalización del discurso entero, un secreto transparente, un diario-diccionario en el cual Stephen Stevensen rinde cuentas solo a la literatura, debido a que los eventos están organizados según los intereses de la imaginación, gracias al desvío o más bien a la difracción: "La forma que adquiere la vida al ser narrada en un diario personal." (p. 121). Pareciera que Piglia se propone representar, dramatizar en "Diario de un loco":

Las interferencias y los saltos por los que se descoloca, y a veces vuelve a 
recolocarse, una identidad u otra [...] lo ficcional es lo real, se cruzan identidades, la atribución de las voces se muda de lugar, se ante-escriben relatos futuros o viceversa, textos o párrafos enteros de diversa proveniencia se superponen al propio entretejido polifónico y jugando a la 'falsedad' a la trampa tendida hacia una (inexistente) tersura (Bratosevich, 1997, p. 301).

En definitiva, "Diario de un loco", al igual que todos los diarios, no escapa a la lógica ambigua que disuelve las fronteras porosas entre la ficción y la realidad, entre lo no-verdadero y lo verdadero. Además lo breve y lo fragmentario y su estructura como diccionario, vistas en su conjunto, constituirían una propuesta que si bien forma un diario, invita a un complejo deslinde de anotaciones que podrían leerse como minificciones.

Por medio de las minificciones queda manifiesta la literaturización de la vida a través de una poética de la reducción que se transforma en cauce expansivo de sentidos plurales, de muchas interpretaciones posibles, convirtiendo a cada lector en cómplice y crítico de esas estrategias narrativas, con las cuales el "Diario de un escritor", lejos de ser la documentación del día a día, es "una variación sobre la capacidad utópica del relato de introducir mundos alternativos en la realidad." (Orecchia, 2006, p. 252). El lector de "Diario de un loco" acepta este fluir desordenado, el permanente salto de una historia a otra, de un tema a otro, de un personaje a otro, legitimado y aceptado por la forma elegida del diario-diccionario que nos permite sostener la hipótesis de que los géneros funcionan como esquemas que Piglia rompe constantemente.

Para concluir, consideramos Encuentro en Saint-Nazaire como texto autobiográfico porque expone un diario íntimo, una proyección encubierta y disimulada de la propia vida y personalidad del autor, porque en los perfiles de la ficción se dibuja una figura donde se reconocen o encuentran parecidos con Ricardo Piglia. Empero, el juego que propone Encuentro en SaintNazaire, es que la ficción puede ser visitada por seres reales. Stephen Stevensen ha tenido un encuentro con un narrador (autoficción del autor) y a su vez este narrador ha traducido y publicado el diario personal de Stephen Stevensen (personaje ficcional), en el cual descubrimos elementos de la vida de Piglia. La intención es exponer que el tránsito entre lo acontecido, lo leído y lo imaginado es tan leve que finalmente se produce la naturalización de la experiencia ficcional contada como real. Así se revela la poética de la literatura pigliana que alimenta la realidad con datos ficcionales, pero también con la propia experiencia personal hasta tal punto que todo en Piglia se convierte en literatura, ya que según él: "La ficción ayuda a pensar. Ayuda a decir cosas muy diversas, porque es un juego donde cada uno tiene su propia visión del mundo, como también sucede en la vida. La ficción permite experimentar con más libertad lo que podríamos llamar la escritura verdadera entre comillas" (2015).

Por otra parte, Encuentro en Saint-Nazaire desarrolla un discurso sobre el acto de escribir y leer ficciones, creando un "ensamblaje textual que pone en valor la escritura como proceso, en otros términos, asume plenamente que toda escritura es una reescritura." (Estrade, 2007, p. 8). También observamos que hay un diálogo con el género diario íntimo por parte del autor, quien se aprovecha de sus características para experimentar con él y transgredirlo, tal y como afirma González (2009):

Piglia halla en este peculiar diario un nuevo cauce de experimentación narrativa cuya idiosincrasia se adecua a las pretensiones fragmentarias de su literatura por cuanto en el espacio de una entrada léxica asistimos a una alianza de materiales heteróclitos donde el ensamblaje entre los distintos significados ofrecidos es 
mínimo, con un dominio de la parataxis propio, por otro lado, de la escritura de un 'loco' como Stephen Stevensen (p. 138).

En resumen, para Piglia existe un diario íntimo que transforma y que en términos de Bajtín sería un "hibrido intencional", donde el autor juega conscientemente con la noción del género, el cual presenta en la nouvelle en forma de diario-diccionario, donde la escritura fragmentaria, confesional y vivencial del diario "articula una intriga sobre el propio proceso de escritura, constituye una genealogía invertida. Al colocar en el pasado lo que vendrá, provoca el disloque lógico y el desfasaje cronotópico: es un relato que sucederá en el futuro." (Berg, 2000, p. 68). De esta forma, el autor logra un inestable y raro equilibro entre lo real y lo ficticio; un discurso subjetivo, personal y verdadero que a la vez es subvertido para imponer una escritura que rebasa lo autobiográfico y se convierte en narración, espacio donde el autor inventa sus múltiples representaciones: Stephen Stevensen, Emilio Renzi.
A propósito, este último escribe en la entrada del 31 de diciembre de 1965 de su diario, publicado por Ricardo Piglia en 2015, lo siguiente: "Releer mis cuadernos es una experiencia novedosa, quizá se puede extraer, de esa lectura, un relato. Todo el tiempo me asombro, como si yo fuera otro (y es lo que soy)". Con estas palabras confirmamos que Piglia es el verdadero sujeto de su diario, no obstante este ocupa un espacio en la escena literaria a través de Renzi, tal y como lo hizo en Encuentro en Saint-Nazaire, allá por 1988 con Stevensen.

\section{Referencias}

Alberca, M. (2007). El pacto ambiguo. De la novela autobiográfica a la autoficción. Madrid: Biblioteca Nueva.

Amiel, H. (1996). En torno al diario intimo. (L. Freixas, trad.). Buenos Aires: PreTextos.

Bajtín, M. (1985). Estética de la creación verbal. El problema de los géneros discursivos. (T. Bubnova, trad.). México: Siglo XXI.

Berg, E. (2000). El relato ausente. (Sobre la poética de Ricardo Piglia). En: Ricardo Piglia. Al cuidado de Jorge Fornet. (pp. 65-85). Colombia, Bogotá: Fondo Editorial Casa de las Américas/Instituto Caro y Cuervo.

Bratosevich, N. et al. (1997). Ricardo Piglia y la cultura de la contravención. Argentina: Atuel.

Di Tella, A. (2015). Los diarios de Piglia se convierten en una película. Entrevista con Patricia Kolesnicov. Recuperado el 10 de octubre de 2015, de http://www.revistaenie.clarin.com/literatura/Di_tellaPigliaLos_diarios_de_Emilio_Renzi_0_1373263014.html

Didier, B. (1976). Le journal intime. París: Presses Universitaires de France, P.U.F.

Doubrovsky, S. (1977). Fils. Paris: Gallimard. 
Estrade, C. (2007). La genèse de la fiction dans les nouvelles de Ricardo Piglia. Recuperado el 30 de diciembre de 2007, de http://www.revuerectoverso.com/IMG/pdf/-article_estrade_corrige.pdf

Estrade, C. (2007a). Une rencontre à Saint-Nazaire: le journal intime tourné vers l'avenir. Revue Recto/ Verso, 2. Recuperado el 20 de julio de 2011, de www.revuerectoverso.com/.../-article_estrade_co...

Friera, S. (2015). La ficción como experiencia de vida. Ricardo Piglia, después de haber ganado el Premio Formentor de las letras. Recuperado el 15 de octubre de 2015, de http://www.pagina12.com.ar/ diario/suplementos/espectaculos/4-35762-2015-06-10.html

Girard, A. (1996). El diario como género literario. Revista de Occidente, (182-183), 31-39.

Gombrowicz, W. (2005). Diario (1953-1969). Barcelona: Seix-Barral.

González Álvarez, J. M. (2009). En los bordes fluidos. Formas híbridas y autoficción en la escritura de Ricardo Piglia. Berlín: Peter Lang, Perspectivas Hispánicas.

Lejeune, P. (1991). El pacto autobiográfico. La autobiografía y sus problemas teóricos. Antropos: Boletín de información y documentación, (29), 47-62.

Lejeune, P. (2004). La pasión por la autobiografía. Cuadernos hispanoamericanos. Entrevista Manuel Alberca a Philippe Lejeune. (pp. 649-650). Madrid: Instituto Cooperación Iberoamericana.

Orecchia Havas, T. (2006). Máscaras del sujeto y mitos de origen del relato en la narrativa de Ricardo Piglia. En: D. Mesa Gancedo (Coord.). Ricardo Piglia: la escritura y el arte nuevo de la sospecha (pp. 239-261). España: Universidad de Sevilla.

Pereira, M.A. (2001). Ricardo Piglia y sus precursores. Buenos Aires: Corregidor.

Picard, H.R. (1981). El diario como género entre lo íntimo y lo público. Anuario de la Sociedad Española de Literatura General y Comparada, (49), 115-122.

Piglia, R. (2000). Conversación con Ricardo Piglia. En: J. Fornet (comp.). Ricardo Piglia (pp. 17-44). Bogotá: Fondo Editorial Casa de las Americas/Instituto Caro y Cuervo.

Piglia, R. (2005). El último lector. Barcelona: Anagrama.

Piglia, R. (2007). Encuentro en Saint-Nazaire. [1988]. En: Prisión perpetua (pp. 79-150). Barcelona: Anagrama.

Piglia, R. (2008). Más que grandes temas hay grandes formas de narrar. En: S.A. Kohan. Entrevista a Ricardo Piglia. Recuperado el 10 de marzo de 2008, de www.grafein.org/Piglia2.htm.

Piglia, R. (2010). O laboratório do escritor e ficçao e política na literatura argentina. Enquete. Piglia fala com Marcia Ivana de Lima e Silva (UFRGS). Recuperado el 30 de abril de 2010, de http://www. ufrgs.br/cdrom/piglia/piglia.pdf.

Piglia, R. (2012). Diarios de escritor. En: I. Bajter y A. Larre Borges. Una conversación con Ricardo Piglia. Recuperado el 12 de junio de 2012 de, http://revistaliterariaazularte.blogspot.com.ar/2012/04/ ignacio-bajter-ana-ines-larre-borges.html 
la palabra

Piglia, R. (2015). Los diarios de Emilio Renzi. Años de formación. Barcelona: Anagrama.

Quintana, I. (2001). Figuras de la experiencia en el fin de siglo: Cristina Peri Rossi, Ricardo Piglia, Juan José Saer. Rosario: Beatriz Viterbo. 